\title{
MiR-185-5p targets RAB35 gene to regulate tumor cell-derived exosomes-mediated proliferation, migration and invasion of non- small cell lung cancer cells
}

\author{
Hongqing Wen ${ }^{1,}$, Zhiyan Liu ${ }^{1,}{ }^{*}$, Jingjing Tang ${ }^{1}$, Lina Bu ${ }^{1}$ \\ ${ }^{1}$ Department of Respiratory and Critical Care Medicine, Xi'an No. 3 Hospital, The Affiliated Hospital of Northwest \\ University, Xi'an 710018, Shaanxi, P.R. China \\ *Equal contribution
}

Correspondence to: Lina Bu; email: bolina2006@stu.xjtu.edu.cn

Keywords: non-small cell lung cancer (NSCLC), miR-185-5p, RAB35, exosomes

Received: August 25, $2020 \quad$ Accepted: August 14, $2021 \quad$ Published: September 9, 2021

Copyright: (C) 2021 Wen et al. This is an open access article distributed under the terms of the Creative Commons Attribution License (CC BY 3.0), which permits unrestricted use, distribution, and reproduction in any medium, provided the original author and source are credited.

\section{ABSTRACT}

Introduction: Non-small cell lung cancer (NSCLC) is the most common malignant tumor, and its recurrence and metastasis are the main causes of death. Recently, there is evidence that tumor derived exosomes play an important role in the occurrence and development of NSCLC.

Objective's methods: First, the expression of miR-185-5p and RAB35 in NSCLC tissues, paracancerous tissues, NSCLC cell lines and normal human bronchial epithelial cell line was detected. Then, a series of gain-and loss-offunction assays were performed to validate the effects of miR-185-5p or RAB35 effects on A549 and H2170 cells proliferation, migration and invasion. Next, online bioinformatics analysis and luciferase reporter were used to predict and validate the targeting relationship of miR-185-5p and RAB35. Finally, tumor cell-derived exosomes with genetic downregulation of RAB35 or overexpression of miR-185-5p were co cultured with their parental cells to verify the regulatory role of RAB35 on exosome secretion and function.

Results: In NSCLC tissues and cell lines, miR-185-5p was downregulated, while RAB35 was significantly upregulated. Overexpression of miR-185-5p or knockdown of RAB35 expression inhibited cell proliferation, migration and invasion. Furthermore, we elucidated that RAB35 is a direct target of miR-185-5p. Additionally, exosomes derived from tumor cells restored cell proliferation, migration and invasion, whereas exosomes secreted by tumor cells with downregulation of RAB35 expression or overexpression of miR-185-5p lost their ability to restore cell proliferation, migration and invasion.

Conclusions: Our results demonstrate that miR-185-5p inhibits tumor cell-derived exosomes-mediated proliferation, migration and invasion of NSCLC cells by downregulating RAB35 expression.

\section{INTRODUCTION}

Lung cancer is a highly prevalent malignancy of the respiratory system, which can be divided into non-small cell lung cancer (NSCLC) and small cell lung cancer (SCLC). NSCLC accounts for $80 \%-85 \%$ of all lung cancers, with lung adenocarcinoma, squamous cell carcinoma, and large cell carcinoma being the most common [1]. There is a study showing that in renal cell carcinoma progression, miR-126 attenuates the ability of renal cell carcinoma cells to invade and metastasize by targeted inhibition of Rock1 expression [2]. Pan et al. reported that miR-370 was able to inhibit hepatocellular carcinoma progression, which was mediated by targeted inhibition of the expression of PIM1 [3]. Similarly, Yang et al. collected tumor tissues from glioma patients and 
found that miR-155 was highly expressed by RT qPCR assay, and mechanistic studies showed that miR-155 could promote tumor cell growth by inhibiting caudal type homeobox 1 (CXD-1) [4]. Recently, emerging evidence has demonstrated that miR-185-5p is expressed at low levels in NSCLC cells and the growth of tumor cells is inhibited when miR-185-5p is overexpressed [5].

RAB GTPases belong to one of the important members of the Ras superfamily of small GTPase proteins, and RAB GTPases are expressed in almost all cells [6]. RAB GTPases have been found to be closely associated with transmembrane transport in cells, where they can form active membrane structures and associate with corresponding proteins, affecting extracellular vesicle formation, transport, and fusion [7]. It has been reported that the expression of rab27b, which is the main component of vesicles in exosomes, is significantly correlated with histological types of lung cancer patients, and lung cancer patients with high rab27b expression have a poor prognosis [8]. Hsu Chieh et al. reported that loss of RAB35 function aggravates the accumulation of intracellular vesicles in oligodendrocytes and decreases the number of extracellular vesicles, suggesting that Rab35 plays a direct role in exosome synthesis and secretion [9].

Exosomes are a type of membranous vesicles secreted by cells into the extracellular matrix, which are approximately $30-100 \mathrm{~nm}$ in diameter and are usually released outside the cell upon fusion of intracellular vesicles with the cell membrane. Studies have found that exosomes can be secreted by almost all types of cells including tumor cells [10]. Currently, researchers have identified exosomes in plasma, CSF, urine, breast milk, and saliva. Emerging evidence suggests that exosomes secreted by tumor cells into the extracellular space are able to influence the tumor microenvironment and regulate tumor cell proliferation, invasion, migration, and angiogenesis, which in turn inhibit or promote tumor progression $[11,12]$.

Accumulating evidence suggests that the interaction between miRNAs and Rabs may serve as a new entry point for tumor therapy. Tang et al. showed that miR720 promoted HeLa cell migration by downregulating RAB35 [13]. In lung cancer, miR-296-3p was reported to be involved in A549 cell growth and metastasis by regulating RabL3 expression [14]. However, the specific mechanism of whether miR-185-5p promotes or inhibits the progression of NSCLC by regulating RAB35 expression to affect the synthesis and secretion of exosomes by NSCLC cells remains unclear. Therefore, the present study will further define the specific mechanism by which miR-185-5p targets the RAB35 gene to affect the development and progression of NSCLC cell-derived exosome mediated tumorigenesis, and this study may contribute to the development of potential treatments for NSCLC.

\section{RESULTS}

\section{MiR-185-5p inhibited NSCLC cell growth}

We extracted total RNA and performed RT-qPCR on 35 pairs of NSCLC tumor tissues and adjacent tissues, and the results indicated that miR-185-5p expression was decreased in lung cancer tissues compared with adjacent tissues (Figure 1A). Similarly, miR-185-5p expression was decreased in NSCLC cells (A549, SPCA1, PC 9, H2170 and SK-MES-1) compared with HBECs (Figure 1B).

Our previous results showed that miR-185-5p was down regulated more fold in A549 and H2170 cells, therefore, we will deeply explore the regulatory role of miR-185$5 p$ in tumor progression in these two types of cells. Then, A549 and H2170 cells were transfected with miR-185-5p mimic and the transfection efficiency was shown in Figure 1C, 1D. Furthermore, we observed that the proliferation ability of A549 and $\mathrm{H} 2170$ cells was attenuated upon transfection of miR-185-5p mimics (Figure 2A). Transfection of miR-185-5p mimic inhibited the migration and invasion of A549 and H2170 cells compared with the control (Figure 2B, 2C).

\section{RAB35 siRNA inhibited NSCLC cell growth}

Bioinformatics databases (http://starbase.sysu.edu.cn/) were used to predict the potential target genes of miR185-5p, and RAB35 was screened. We observed no binding relationship between mutated RAN35 and miR185-5p (Figure 3A). Next, we found that miR-185-5p mimic reduced the luciferase activity of wild-type Rab35 but not mutant Rab35 (Figure 3B). Furthermore, the mRNA and protein expression levels of RAB35 in A549 and $\mathrm{H} 2170$ cells were significantly suppressed after transfection with miR-185-5p mimic (Figure 3C, 3D).

Then, we found that the expression of RAB35 was higher in tumor tissues than in adjacent tissues (Figure 4A). Moreover, biological database (http://kmplot.com/ analysis/) exhibited the relationship between RAB35 expression and survival cycle in 1928 lung cancer patients, indicating that the median survival of patients with RAB35 low expression was 99.43 months, while that of patients with RAB35 high expression was only 53 months (Figure 4B). In different NSCLC cell lines, we similarly observed high levels of RAB35 expression (Figure 4C). Next, A549 and H2170 cells were transfected with RAB35 siRNA and the transfection efficiency is shown in Figure 4D. The proliferation 
ability of A549 and H2170 cells was attenuated upon transfection of RAB35 siRNA (Figure 5A). Transfection of RAB35 siRNA inhibited the migration and invasion of A549 and H2170 cells compared with the control (Figure 5B, 5C).

\section{MiR-185-5p inhibited NSCLC cell growth by targeting RAB35}

The A549 and $\mathrm{H} 2170$ cells were transfected with pcDNA-RAB35 alone or together with miR-185-5p mimic. We observed that pcDNA-RAB35 promoted RAB35 protein expression, and miR-185-5p mimic inhibited RAB35 protein expression (Figure 6A). Moreover, the pcDNA-RAB35 promoted cell proliferation in A549 and $\mathrm{H} 2170$ cells. However, the enhanced cell proliferation by pcDNA-RAB35 was reversed by miR-185-5p mimic (Figure 6B). The ability of migration and invasion of A549 and $\mathrm{H} 2170$ cells was enhanced by pcDNA-RAB35, but this change was partially abolished by miR-185-5p mimic (Figure 6C, 6D).
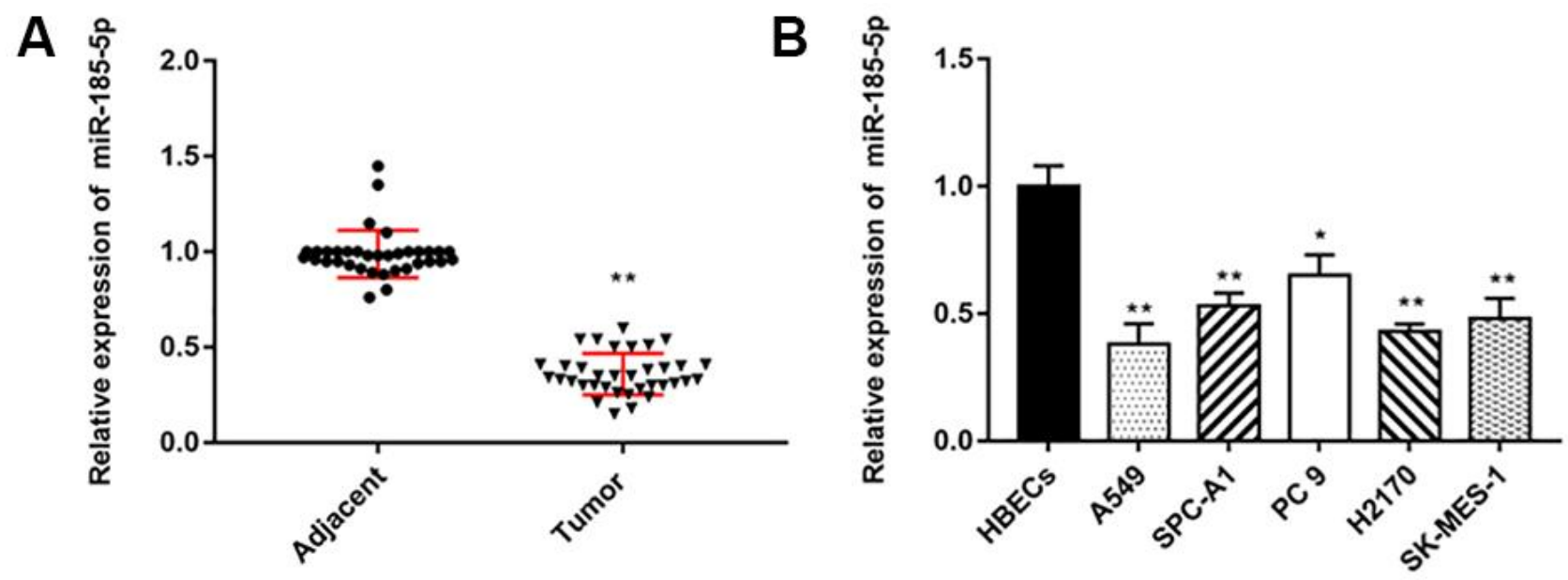

C
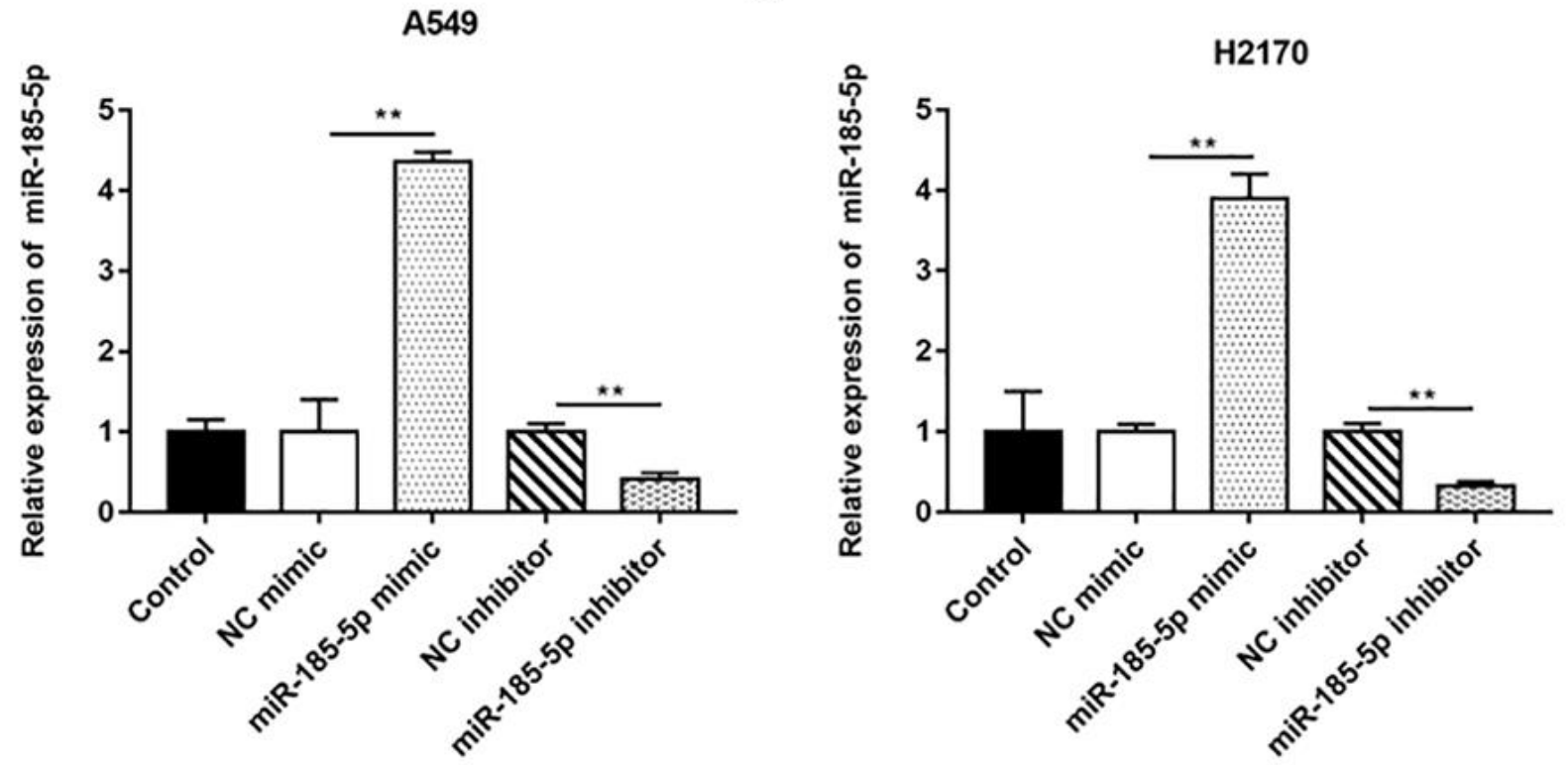

Figure 1. MiR-185-5p is downregulated in NSCLC tissues and cell lines. The NSCLC tissues and tissues larger than $5 \mathrm{~cm}$ around the tumor were collected ( $\mathrm{N}=70,35$ tumor tissues and 35 adjacent tissues). (A) RT-qPCR was used to detect the relative expression of miR-185-5p in tumor tissues and adjacent tissues, and the results showed that miR-185-5p was downregulated in NSCLC tissues. (B) Relative expression of miR-185-5p in NSCLC cell lines (A549, SPC-A1, PC 9, H2170 and SK-MES-1 cells) and normal bronchial epithelial cell line (HBECs) were detected by RT-qPCR assay, and the results showed that miR-185-5p was downregulated in NSCLC cell lines. The miR-185-5p mimic, miR-185$5 p$ inhibitor and their negative control were transfected into A549 cells and H2170 cells, respectively. (C, D) Relative expression of miR-185$5 p$ in A549 cells and $\mathrm{H} 2170$ cells was analyzed by RT-qPCR. N=6, * $P<0.05, * * P<0.01$. 
A

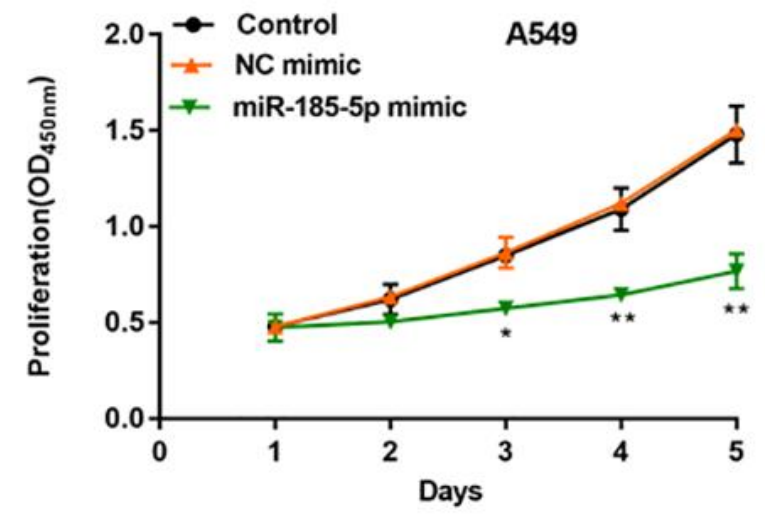

A549

B

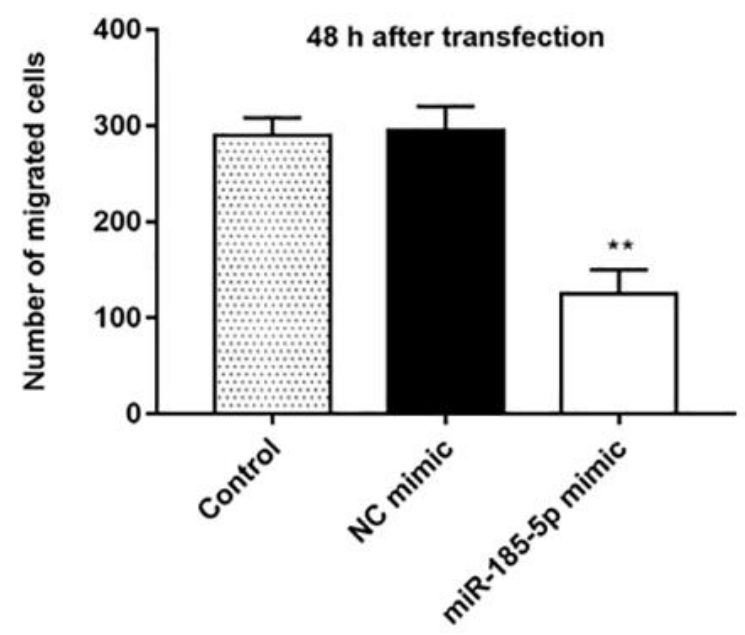

C

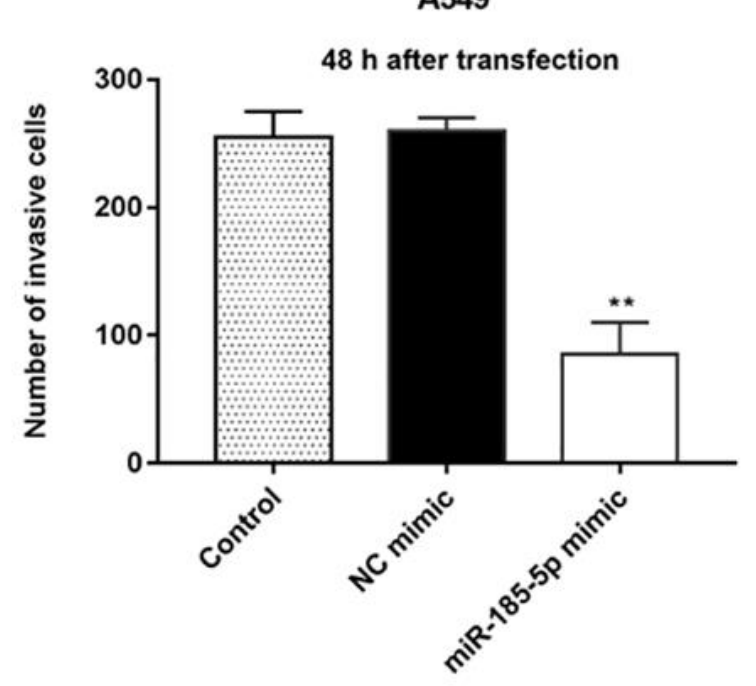

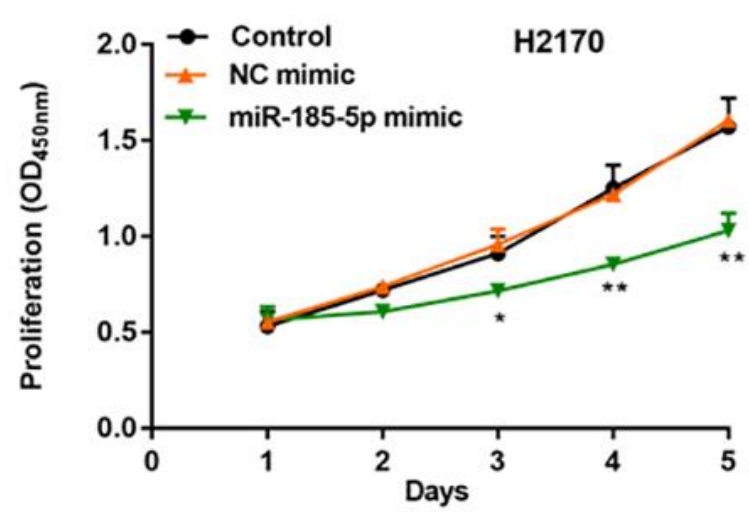

H2170

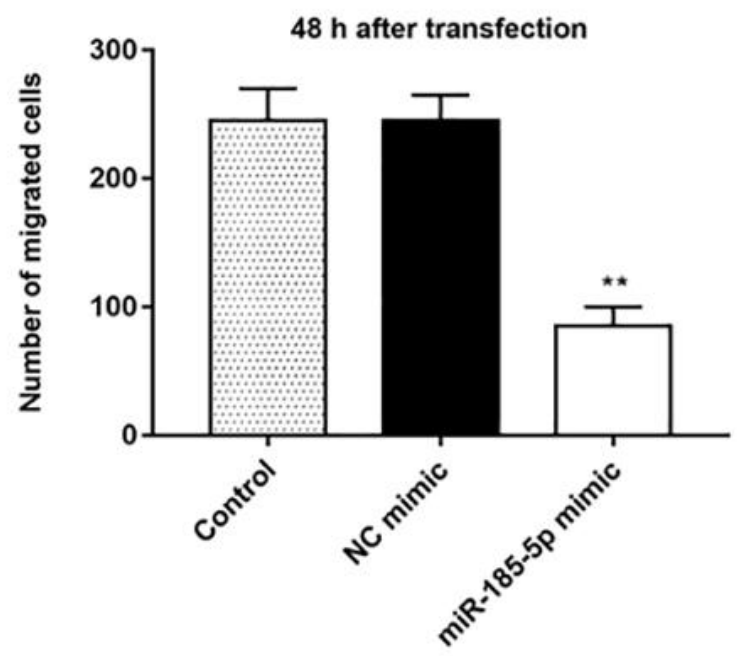

H2170

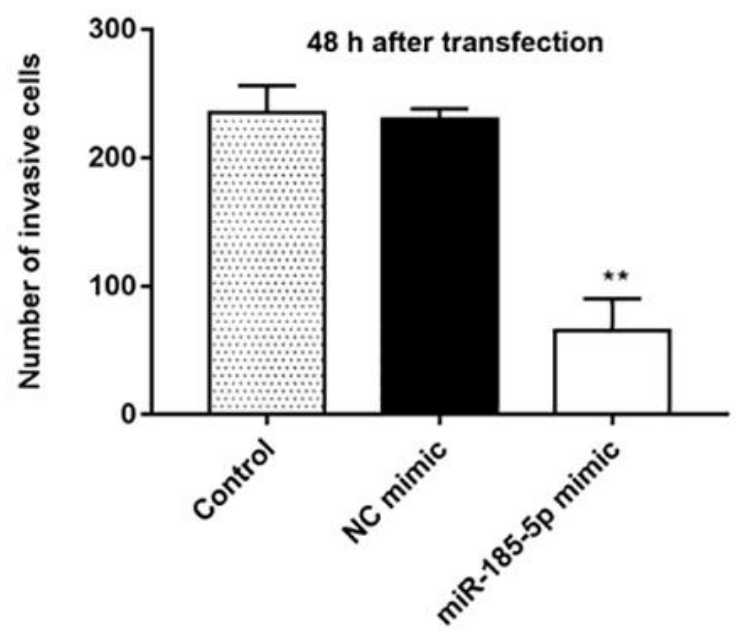

Figure 2. Overexpression of miR-185-5p inhibits proliferation, migration and invasion of NSCLC cells. The miR-185-5p mimic and NC mimic were transfected into A549 cells and H2170 cells, respectively. (A) The proliferation of A549 and H2170 cells was assessed by CCK-8 assay, and the results showed that miR-185-5p mimic inhibited cell proliferation. (B) The migration of A549 and H2170 cells was detected by Transwell cell migration assay, and the results showed that miR-185-5p mimic inhibited cell migration. (C) The invasion of A549 and $\mathrm{H} 2170$ cells was analyzed by Transwell cell invasion assay, and the results showed that miR-185-5p mimic inhibited cell invasion. $\mathrm{N}=6,{ }^{*} P<0.05, * *$ $P<0.01$. 


\section{Effect of RAB35 on exosome secretion from A549 cells}

There have been numerous studies confirming that exosomes secreted by tumor cells promote or inhibit tumor progression by regulating tumor cell growth $[15$, 16]. It is well known that some proteins including CD63, HSP70 and TSG101 are markers for detecting exosomes. A549 and $\mathrm{H} 2170$ cells were transfected with miR-185-5p mimic and RAB35 siRNA for $48 \mathrm{~h}$, and cell culture medium was collected and exosomes were extracted. We found that TSG101 and CD63 proteins were enriched in exosomes secreted by A549 and $\mathrm{H} 2170$ cells but not in A549 and H2170 cells. When overexpressing miR-185-5p or interfering with RAB35, we observed suppressed TSG101 protein and CD63 protein expression in tumor cells and their derived exosomes (Figure 7A, 7B). Moreover, HSP70 protein expression was reduced in exosomes secreted by tumor cells transfected with miR185-5p mimic or RAB35 siRNA (Figure 7C).

\section{Exosomes secreted by tumor cells with RAB35 knockdown inhibited NSCLC proliferation}

Exosomes secreted by A549 and H2170 cells were incubated with A549 and H2170 cells with knockdown of RAB35 expression. We observed that exogenous exosomes restored the proliferation ability of A549 and H2170 cells with knockdown of RAB35 expression (Figure 8A). Further, exosomes secreted by normal A549 cells (transfected with scramble or NC mimic) restored cell proliferation ability compared with A549 cells with knockdown of RAB35 expression (transfected with siRAB35 or miR-185-5p mimic), whereas exosomes secreted by A549 cells with knockdown of RAB35 expression (transfected with siRAB35 or miR-185-5p mimic) again inhibited cell proliferation (Figure 8B). The same results were validated in $\mathrm{H} 2170$ cells.

\section{Exosomes secreted by tumor cells with RAB35 knockdown inhibited NSCLC migration and invasion}

Exosomes secreted by A549 cells were treated with enzymes, and then the enzyme treated exosomes were co incubated with A549 cells with knockdown of RAB35 expression. We observed that cell migration (Figure 9A) and invasion (Figure 9B) were inhibited. The same results were validated in $\mathrm{H} 2170$ cells.
A
B

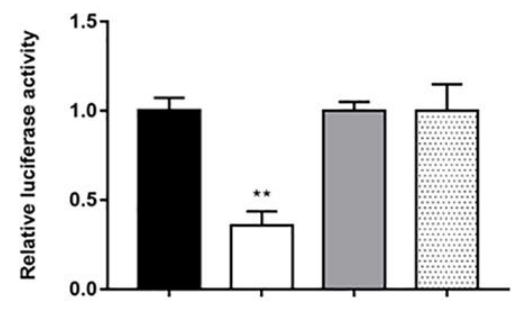

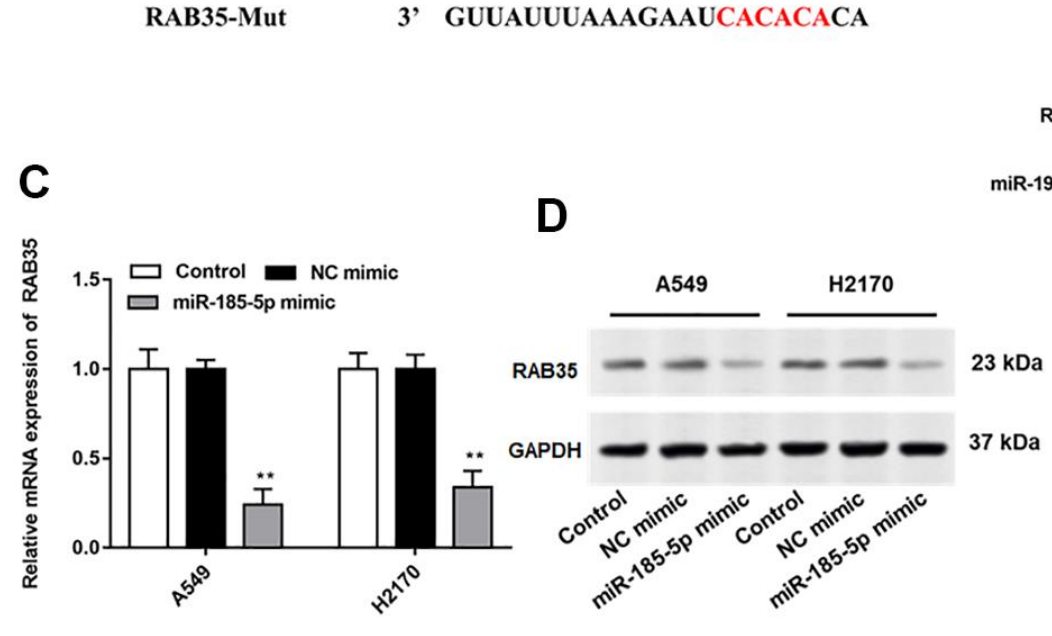

D
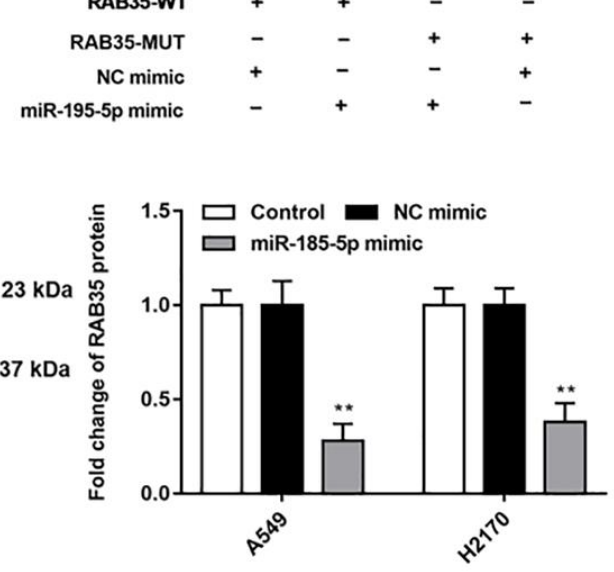

Figure 3. MiR-185-5p directly targets 3'UTR of RAB35. (A) StarBase 3.0 (http://starbase.sysu.edu.cn/) was used to predict the target genes of miR-185-5p, and we found that miR-185-5p binds to RAB35 mRNA 3'UTR. (B) The relative luciferase activity was tested with wildtype and mutant-type RAB35, respectively. (C, D) The miR-185-5p mimic and NC mimic were transfected into A549 cells and H2170 cells, respectively. The mRNA and protein expression of RAB35 in A549 and H2170 cells was analyzed by RT-qPCR and Western blotting, and the results showed that miR-185-5p mimic inhibited mRNA and protein expression of RAB35. $\beta$-actin was used as an invariant internal control for calculating protein-fold changes. $\mathrm{N}=6, * * P<0.01$. 
A

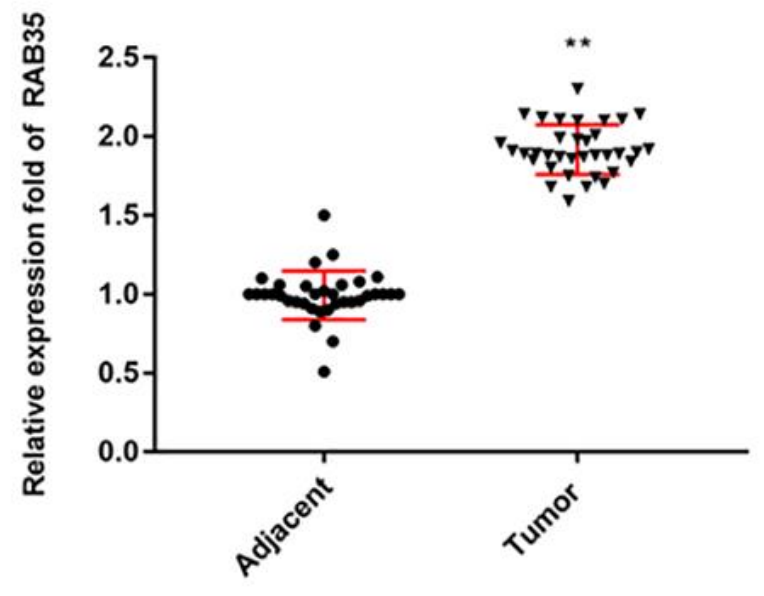

C

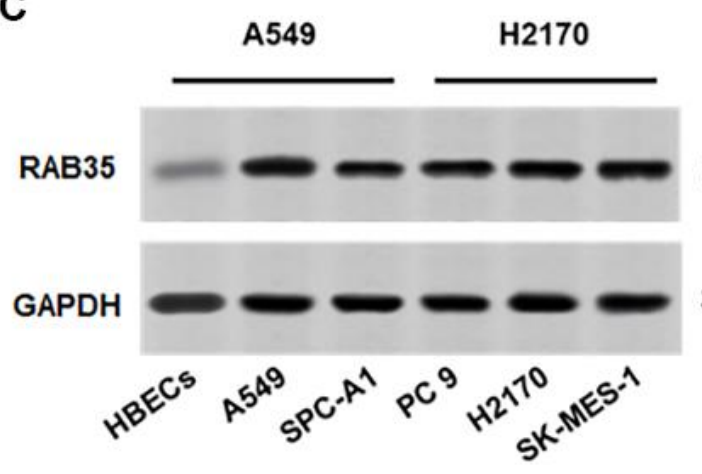

B

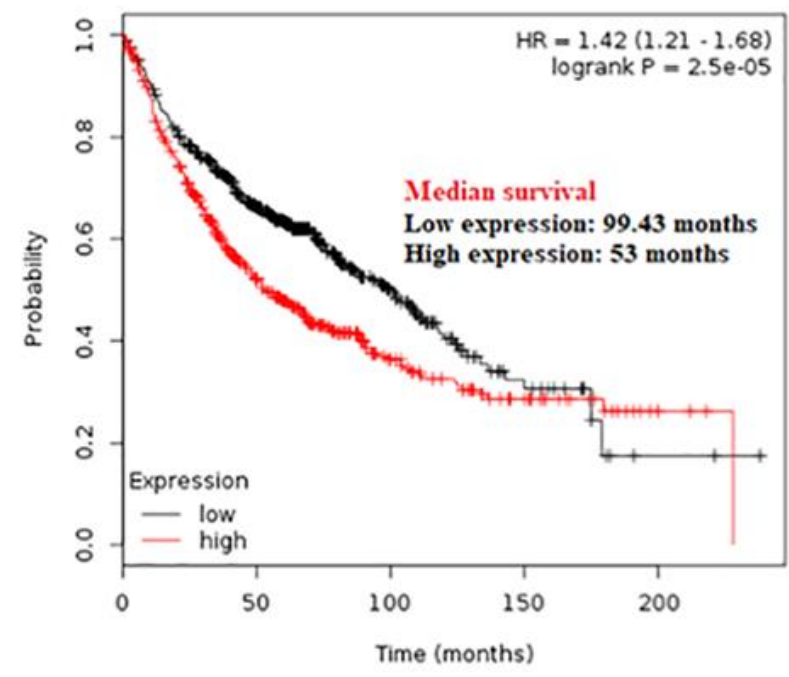

$23 \mathrm{kDa}$

$37 \mathrm{kDa}$
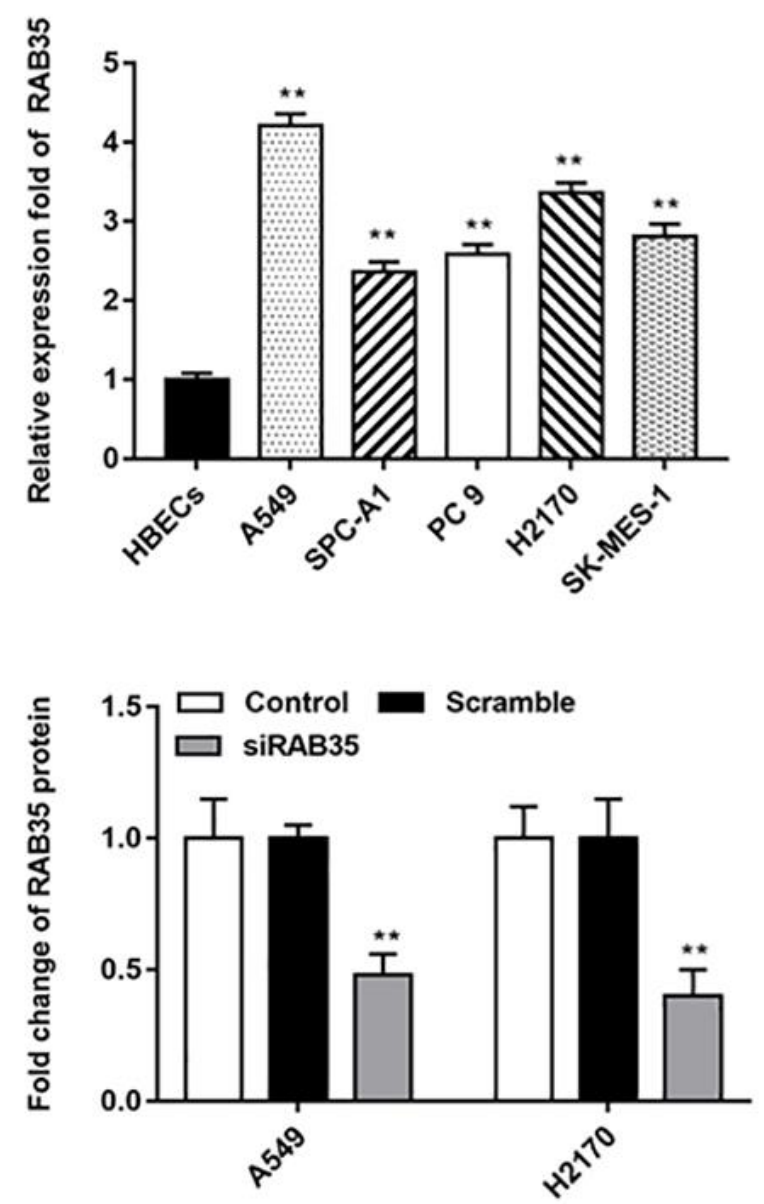

Figure 4. RAB35 is upregulated in NSCLC tissues and cell lines. The NSCLC tissues and tissues larger than $5 \mathrm{~cm}$ around the tumor were collected ( $N=70,35$ tumor tissues and 35 adjacent tissues). (A) RT-qPCR was used to detect the relative expression of RAB35 in tumor tissues and adjacent healthy tissues, and the results showed that RAB35 was upregulated in NSCLC tissues. (B) KM plotter software (http://kmplot.com/analysis/) was used to analyze the expression and survival of RAB35 gene in 1928 lung cancer patients. (C) Western blotting was used to detect the relative protein expression of RAB35 in NSCLC cell lines (A549, SPC-A1, PC 9, H2170 and SK-MES-1 cells) and normal bronchial epithelial cell line (HBECS), and the results showed that RAB35 was upregulated in NSCLC cell lines. (D) RAB35 siRNA and negative control (Scramble) were transfected into A549 cells and $\mathrm{H} 2170$ cells, respectively. The protein expression of RAB35 was analyzed by Western botting. $\beta$-actin was used as an internal reference. $N=6, * * P<0.01$. 
A

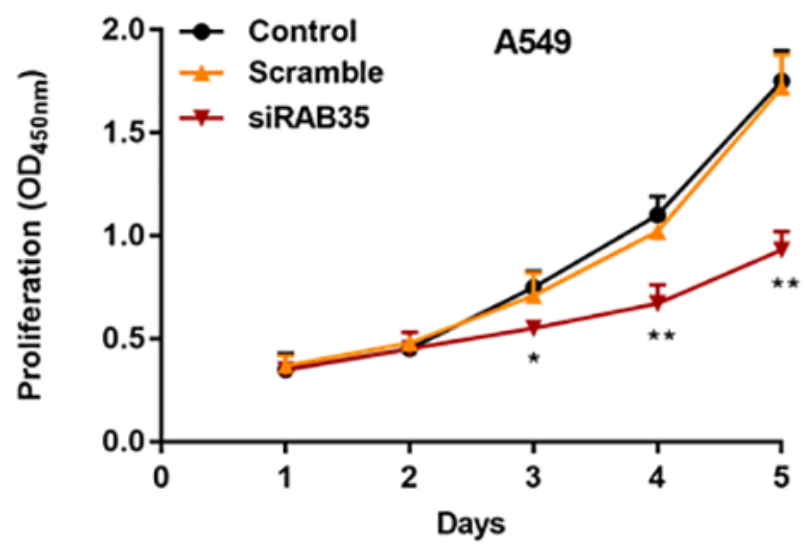

A549

B

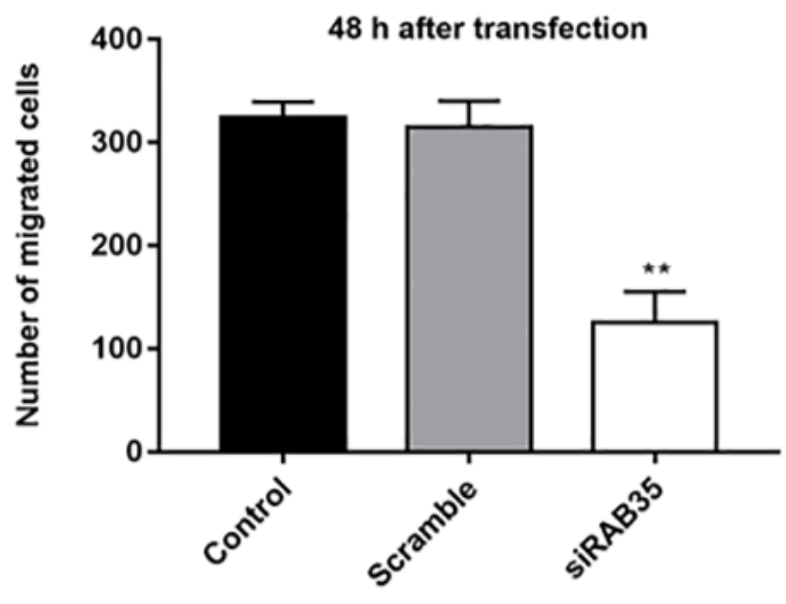

C

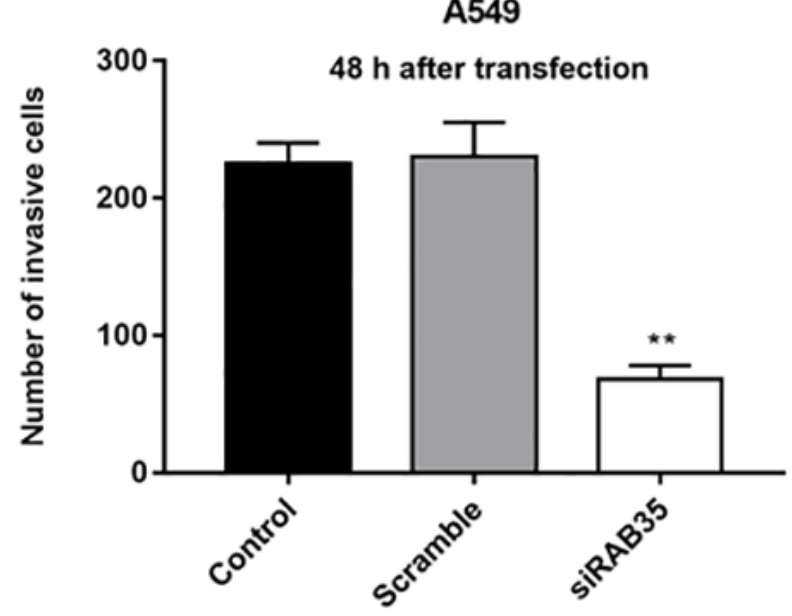

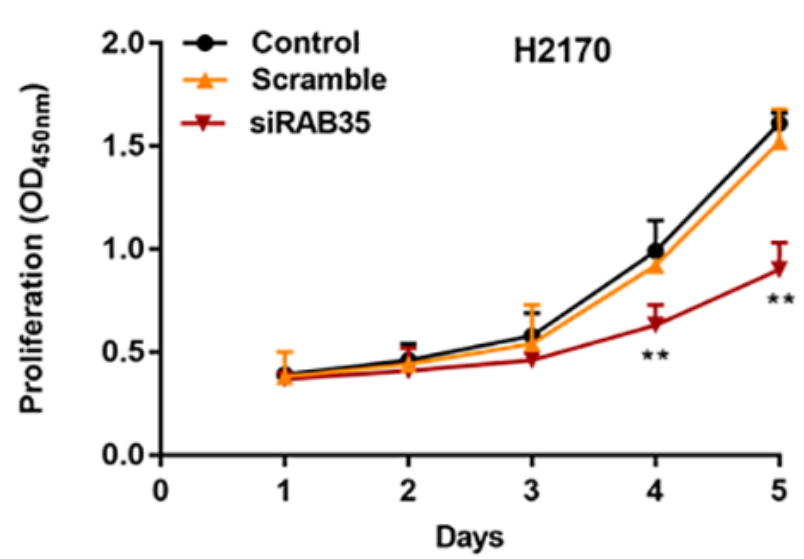

H2170

$48 \mathrm{~h}$ after transfection

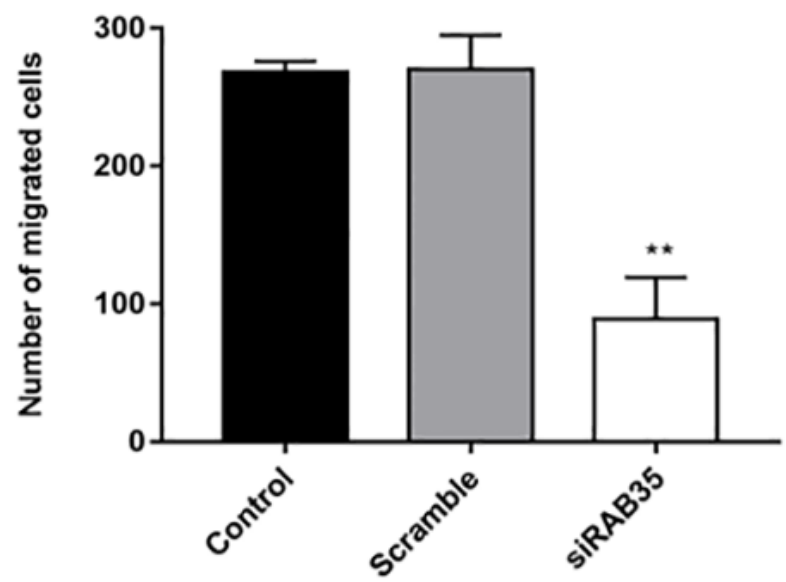

H2170

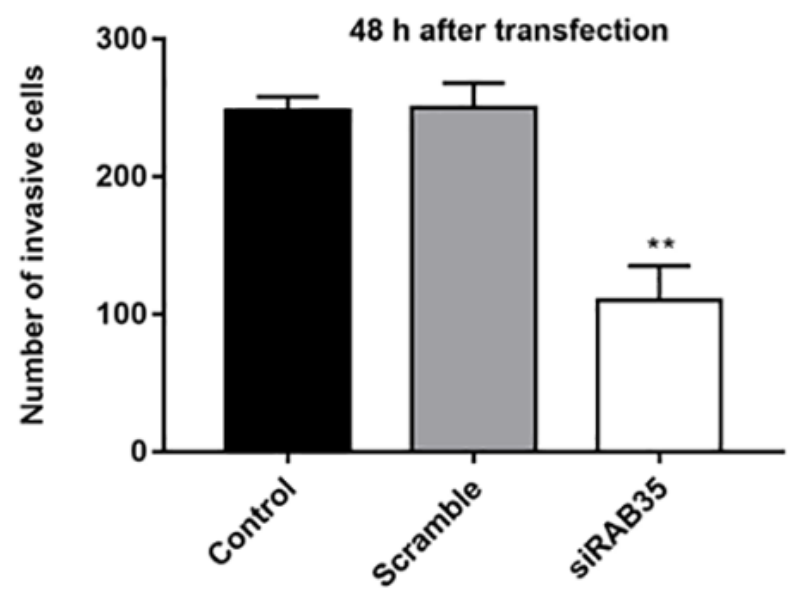

Figure 5. Knockdown of RAB35 inhibits proliferation, migration and invasion of NSCLC cells. RAB35 siRNA and negative control (Scramble) were transfected into A549 cells and H2170 cells, respectively. (A) CCK-8 assay was used to measure the proliferation of A549 and H2170 cells at day 1, 2, 3, 4, 5 after transfection, and the results showed that RAB35 knockdown inhibited cell proliferation. (B) The migration of A549 and H2170 cells was detected by Transwell cell migration assay, and the results showed that RAB35 knockdown inhibited cell migration. (C) The invasion of A549 and H2170 cells was analyzed by Transwell cell invasion assay, and the results showed that RAB35 knockdown inhibited cell invasion. $\beta$-actin was used as the loading control. $\mathrm{N}=6,{ }^{* *} P<0.01$. 

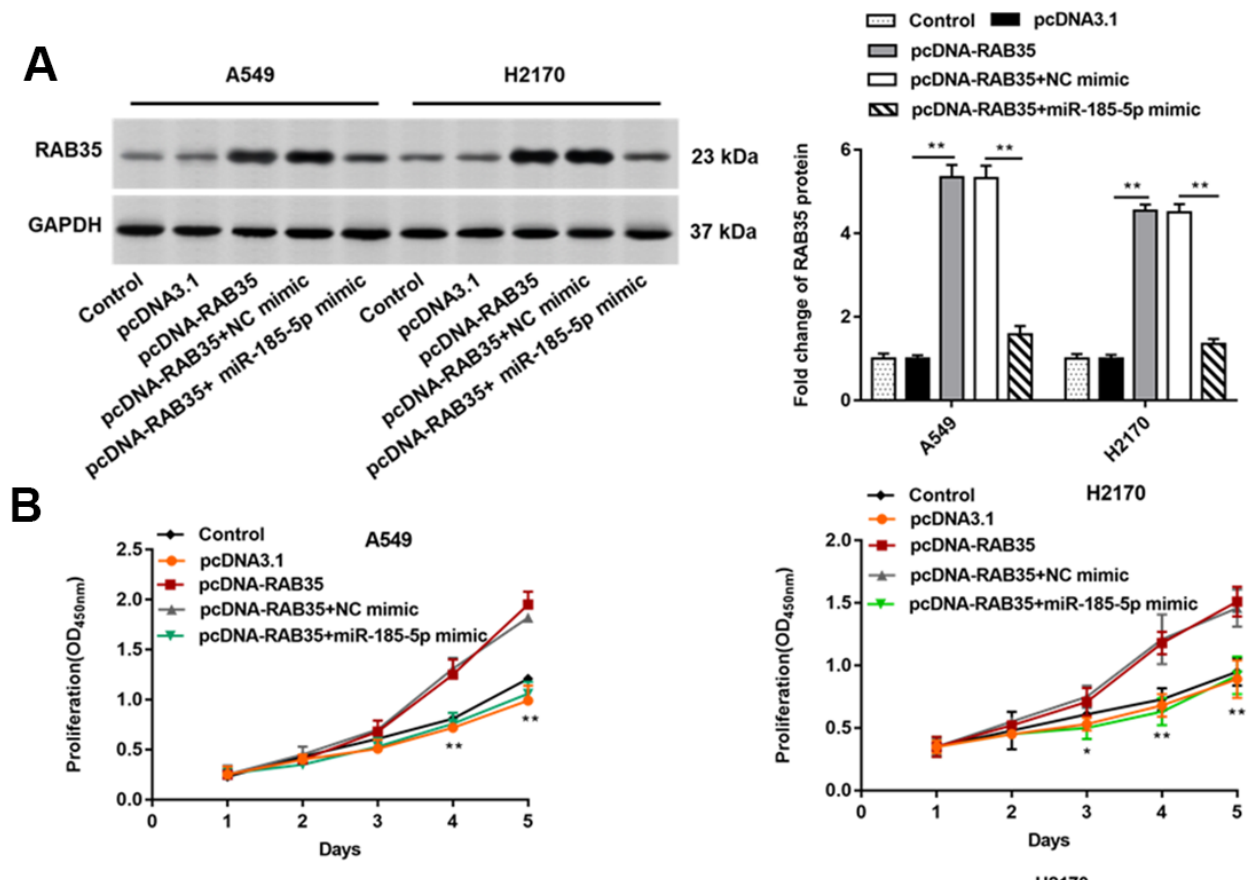

C
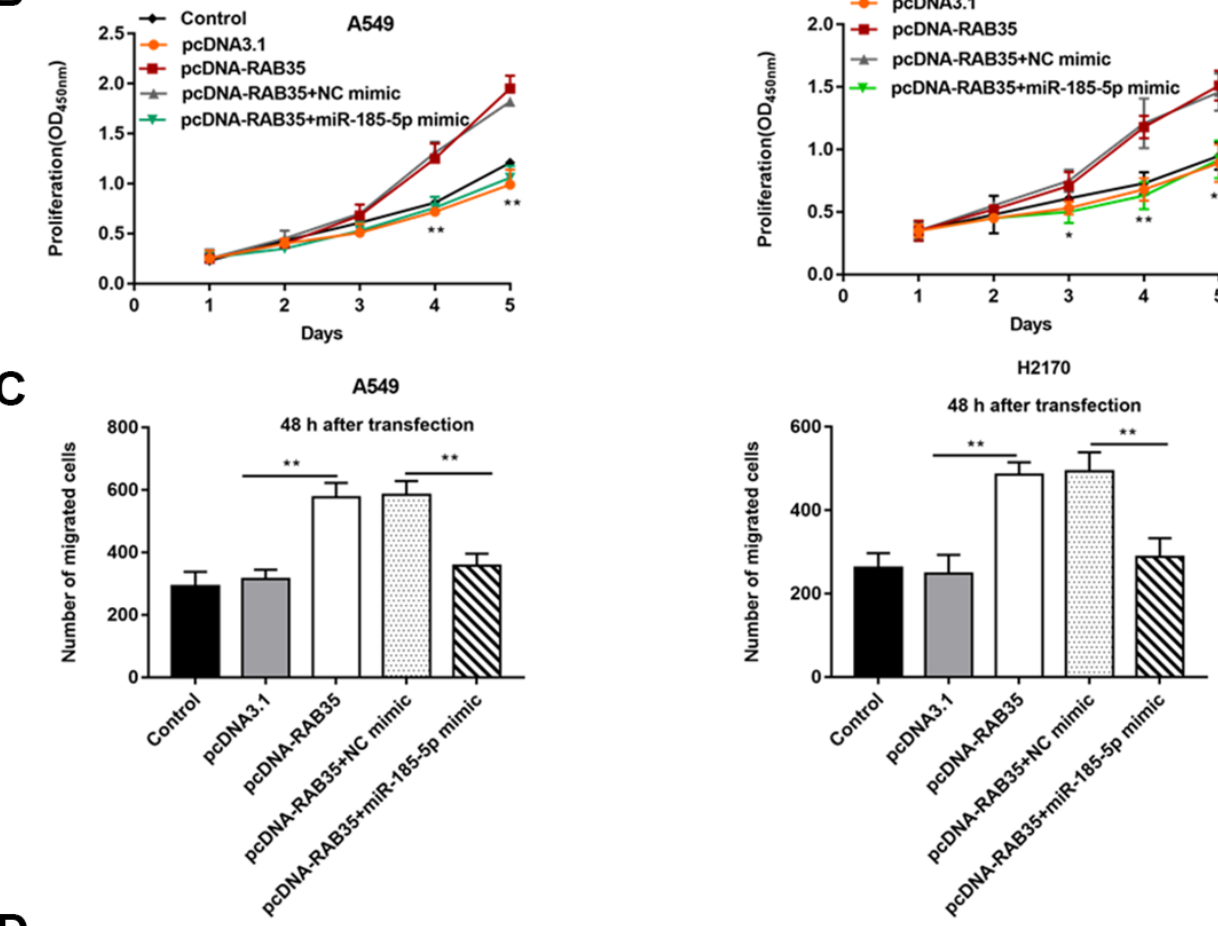

D
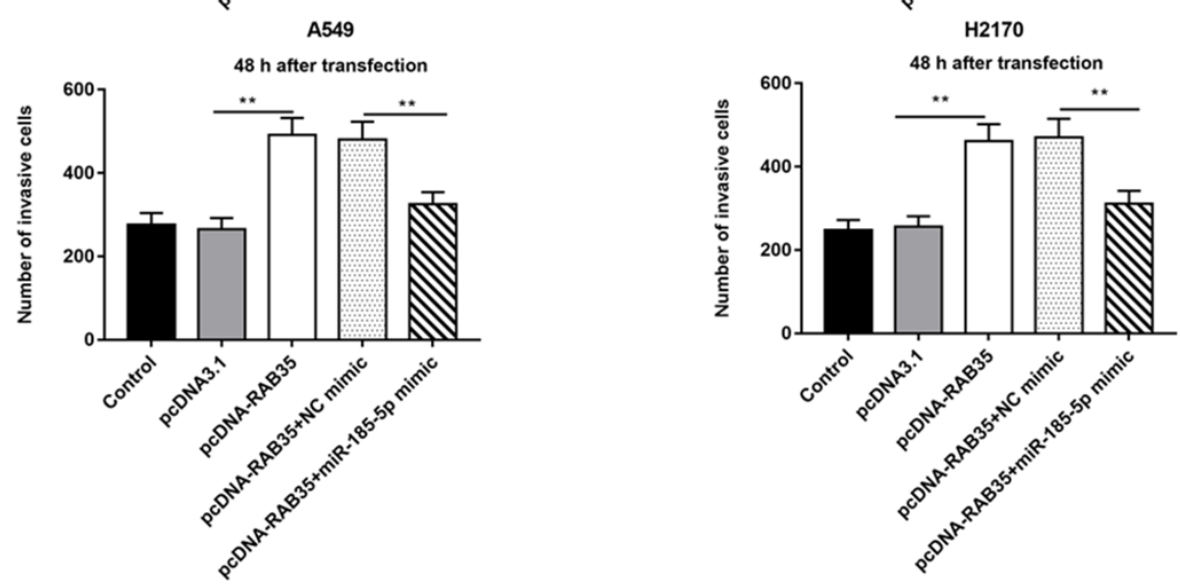

Figure 6. MiR-185-5p inhibits proliferation, migration and invasion of NSCLC cells by targeting RAB35. The pcDNA-RAB35 was transfected into A549 cells and H2170 cells alone or together with miR-185-5p mimic, respectively. (A) Fold change of RAB35 protein was analyzed by Western blotting, and we found that miR-185-5p mimic reversed the promoting effect of pcDNA-RAB35 on RAB35 protein expression. (B) The cell proliferation of A549 and $\mathrm{H} 2170$ cells at day 1, 2, 3, 4, 5 after transfection was measure by CCK-8 assay. (C) Transwell cell migration assay was used to measure the migration of A549 cells and $\mathrm{H} 2170$ cells. (D) The cell invasion was detected by Transwell cell invasion assay. We found that miR-185-5p mimic reversed the promoting effect of pcDNA-RAB35 on cell proliferation, migration and invasion. $\beta$-actin was used as an internal reference. $N=6, * * P<0.01$. 

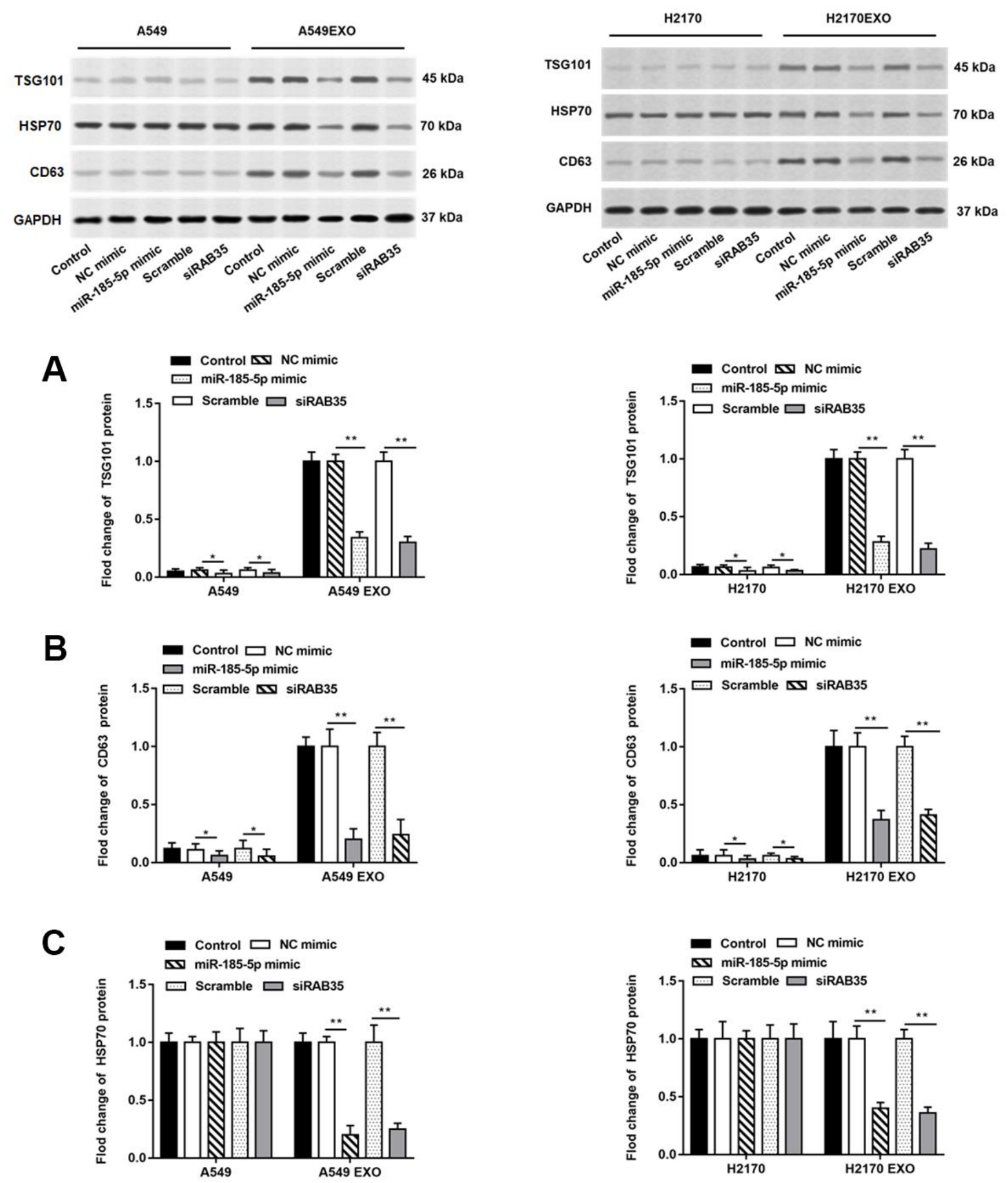

Figure 7. Knockdown of RAB35 reduces the number of exosomes from tumor cells and inhibits its function. The miR-185-5p mimic, RAB35 siRNA and their negative control were transfected into A549 and H2170 cells, respectively. Next, the cell culture medium was collected after 48 hours and extracted exosomes. (A-C) Western blotting was used to detect the relative protein expression of TSG101, CD63 and HSP70 in A549 cells, H2170 cells and their secreted exosomes, and the results suggested that exosomes isolated from A549 and H2170 cells transfected with miR-185-5p mimic and siRAB35 had lower protein expression of TSG101, CD63 and HSP70. $\beta$-actin was used as an invariant internal control for calculating protein-fold changes. $\mathrm{N}=6,{ }^{* *} P<0.01$. 
Diminished ability of exosomes derived from A549 cells overexpressing miR-185-5p to induce tumorigenesis in nude mice

Nude mice tumor bearing models were constructed by intraperitoneal injection of A549 cells, and the normal saline, A549 cell-derived exosomes, A549 cell (transfected with $\mathrm{NC}$ mimic)-derived exosomes and A549 cell (transfected with miR-185-5p mimic)-derived exosomes were injected into nude mice, respectively. We observed that A549 cell-derived exosomes induced tumorigenesis more readily than A549 cells, as indicated by the larger volume and weight of the tumors formed in nude mice, and the representative tumor images are shown in Figure 10A. Furthermore, the volume (Figure 10B) and weight (Figure 10C) of tumors formed by exosome treated nude mice derived from 549 cells overexpressing miR-185-5p were significantly reduced compared to those from exosome treated nude mice derived from normal A549 cells (transfected with NC mimic).

\section{DISCUSSION}

Studies have shown that miR-185-5p is able to regulate the growth of a variety of tumor cells, and it affects the prognosis of patients. The investigators found that miR$185-5 p$ attenuated the proliferative capacity of tumor cells, promoted tumor cell apoptosis, and delayed prostate cancer progression by downregulating RNCR3 expression [17]. Yu et al. reported that miR-185-5p was under-expressed in lung squamous cell carcinoma tumor tissues and NSCLC cell lines, and low miR-185-5p expression was an independent risk factor for poor

\section{A}
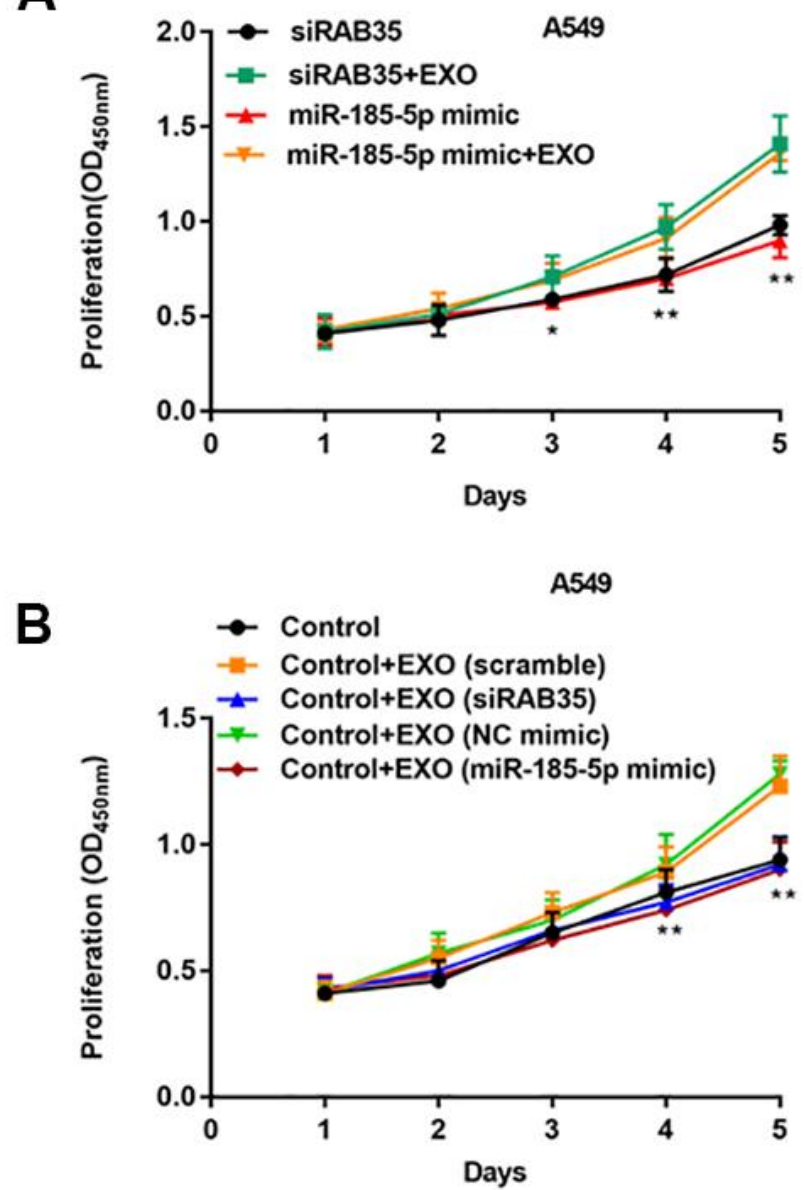

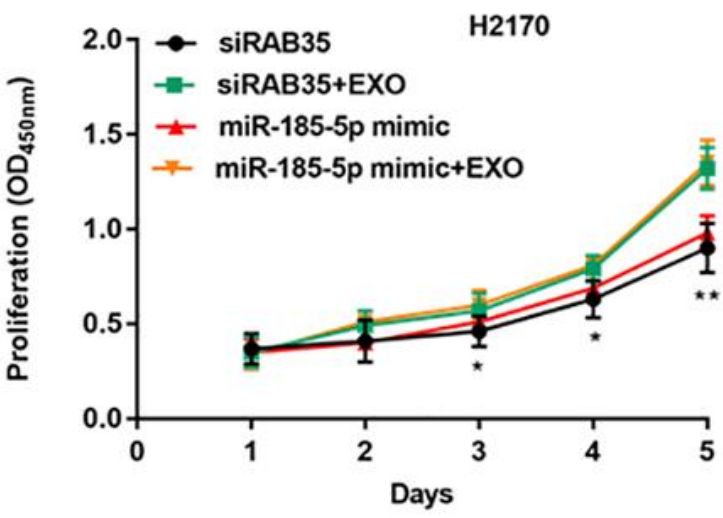

H2170

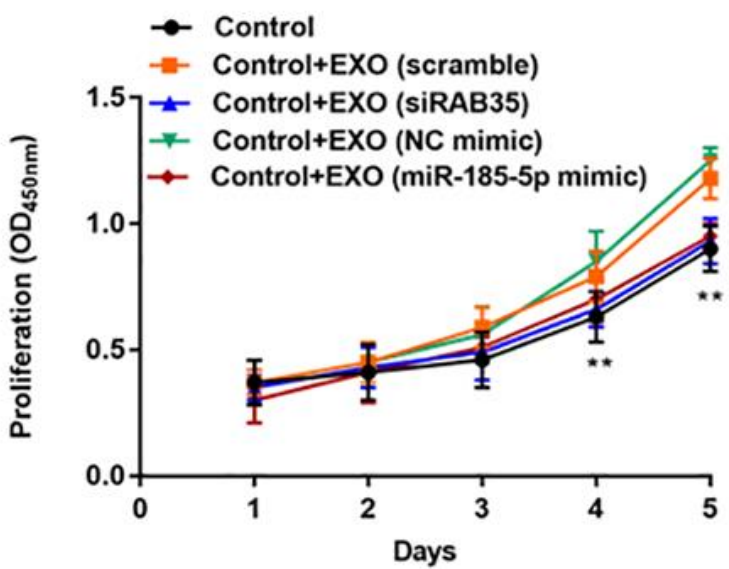

Figure 8. NSCLC cell-derived exosomes with RAB35 knockdown or miR-185-5p overexpression inhibit NSCLC cell proliferation. (A) A549 cells (H2170 cells) with knockdown of RAB35 or overexpression of miR-185-5p were incubated with exosomes secreted by $A 549$ cells ( $\mathrm{H} 2170$ cells). CCK- 8 assay was used to measure the proliferation of A549 and $\mathrm{H} 2170$ cells at day 1, 2, 3, 4, 5 after transfection. (B) RAB35 siRNA was transfected as negative control group and co-cultured with the exosomes secreted by RAB35 downregulated or miR-185-5p overexpression A549 cells and H2170 cells, respectively. The cell proliferation was measure by CCK-8 assay. $\mathrm{N}=6, * * P<0.01$. 
patient prognosis [18]. Additional studies reported that LncRNA MALAT1 and MDM4 were upregulated in NSCLC cells. MiR-185-5p, a MALAT1 target, can directly target MDM4 and significantly inhibit NSCLC cell growth when overexpressed [5]. Pei et al. reported that miR-185-5p was highly expressed in normal A549 cells compared with cisplatin sensitive A549 cells, and the sensitivity of A549 cells to cisplatin was increased when miR-185-5p mimic were transfected, while miR185-5p inhibitor promoted cisplatin resistance in A549 cells [19]. In the present study, we found that miR-185$5 \mathrm{p}$ was downregulated in NSCLC tissues and cell lines, and overexpression of miR-185-5p inhibited the proliferation, migration, and invasion of NSCLC cells. Moreover, RAB35 was identified as a target gene of miR-185-5p, and RAB35 overexpression plasmid reversed the regulatory effect of miR-185-5p on NSCLC cells.

Numerous studies have proved that the high expression of RAB35 was related to the malignancy degree and poor prognosis of tumors. Zhu et al. found that RAB35 expression increased in MCF-7 breast cancer cells, and significantly inhibited Wnt5a-induced cell proliferation after knocking down RAB35 expression A study showed that RAB35 was abnormally highly expressed in breast cancer cells MCF-7, and when RAB35 expression was inhibited, Wnt5a induced cell proliferation was also inhibited [20]. Duan et al. reported that upon silencing of RAB35, the stability of GIT2 was disrupted, and the level of phosphorylation was reduced, further inhibiting the polarization and
A

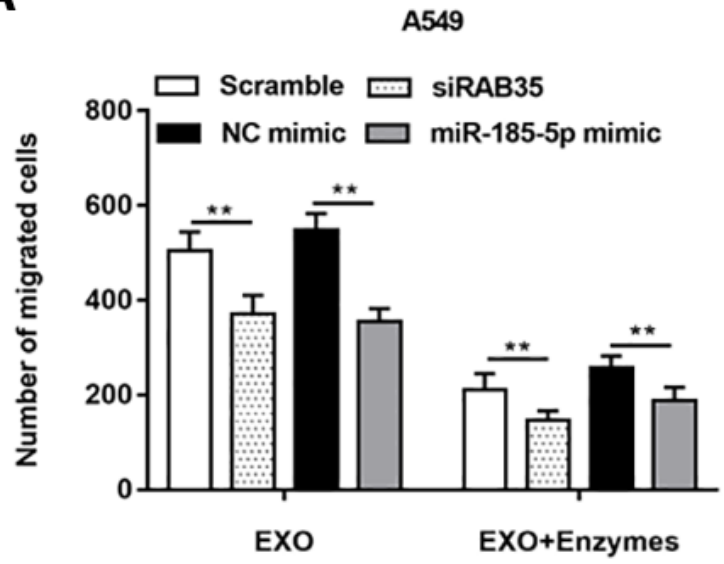

B

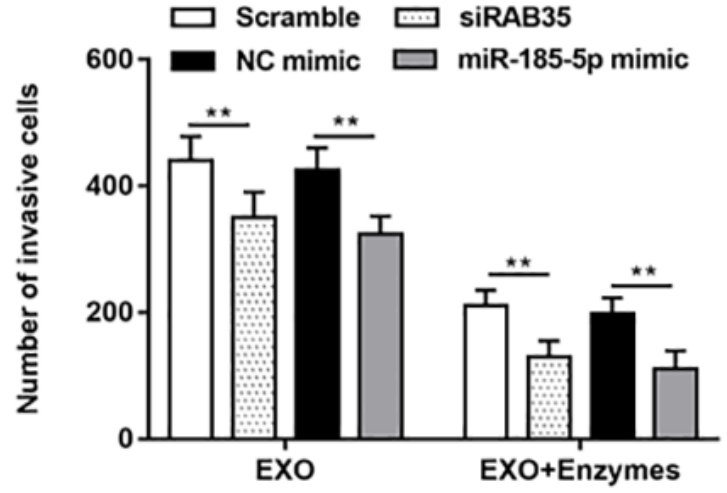

H2170

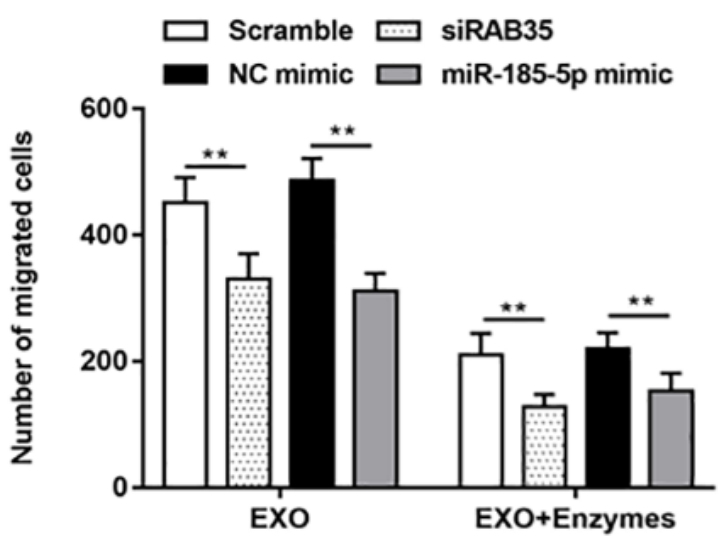

H2170

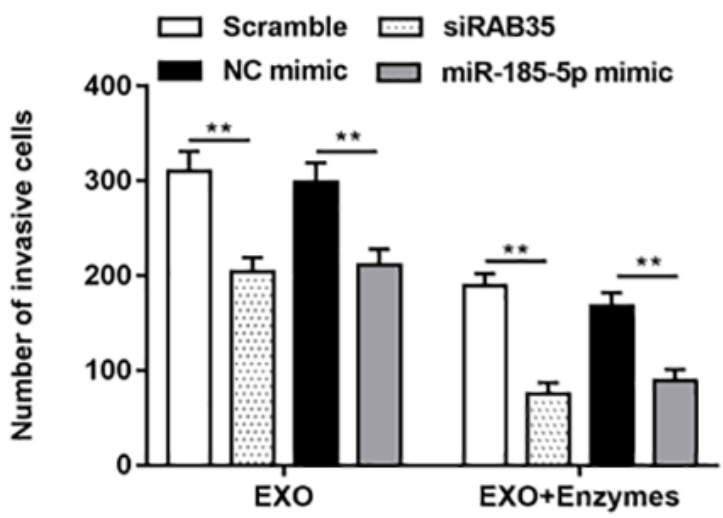

Figure 9. NSCLC cell-derived exosomes with RAB35 knockdown or miR-185-5p overexpression (Enzyme treated) inhibited NSCLC cell migration and invasion. The exosomes secreted by A549 cells and $\mathrm{H} 2170$ cells were treated with enzyme and then added into the two kinds of cell models with downregulation of RAB35. (A) Transwell cell migration assay was used to measure the migration of A549 cells and H2170 cells, and the results showed that the promoting effects of exosomes secreted by A549 and H2170 cells on cell migration and invasion were attenuated under the action of enzymes. (B) The cell invasion was detected by Transwell cell invasion assay. $\mathrm{N}=6, * * P<0.01$ 
migration of NSCLC cells [21]. In addition, RAB35 was identified as a binding protein of lncRNA HOTAIR and its expression was positively regulated by RNA HOTAIR, accelerating the metastasis of hepatocellular carcinoma cancer cells [22]. In a study related to leukemia, investigators found that RAB35 has a strong promoting effect on cancer cell invasion, metastasis and immune escape [23]. The above reports further corroborate our findings and suggest that RAB35 plays an important role in NSCLC progression.

Exosomes are important components that constitute the tumor microenvironment and can participate in angiogenesis to accelerate tumor progression through intercellular information communication [24, 25]. For example, mesenchymal stem cells undergo morphological and functional alterations under the stimulation of exosomes secreted by colorectal cancer cells, and this change will further affect tumor cell growth and metastasis [26]. Wu et al. suggested that the NF- $\mathrm{BB}$ pathway in macrophages was rapidly activated upon stimulation by exosomes secreted by gastric cancer cells, accelerating tumor metastasis [27]. Another study found that exosomes were able to mediate membrane transport of metastasis associated protein 1 (MTA1) in breast cancer cells, which had a positive regulatory effect on hypoxia and estrogen signaling [28]. As an important part of tumor microenvironment, exosomes play an important role in the process of drug resistance. Similarly, $\mathrm{Qu}$ et al. reported that sorafenib induced apoptosis was abrogated under exosome intervention, resulting in decreased drug sensitivity of hepatocellular carcinoma cells, leading to poor prognosis of liver cancer patients [29]. In this study, we found that the synthesis and secretion of exosomes were inhibited in A549 and H2170 cells after transfection with siRAB35 or miR-185-5p mimic. Furthermore, we found that exosomes secreted by A549 and $\mathrm{H} 2170$ cells were able to restore the growth of parental cells, suggesting that exosomes play an important role in NSCLC progression.

In this study, a nude mouse tumor bearing model was constructed by intraperitoneal injection of A549 cells to investigate the effects of A549 cell-derived exosomes on tumor progression. In fact, we first consider to establish the lung orthotopic xenograft tumor nude mice model, unfortunately, the results are unsatisfactory, which is also a pitfall of in vivo studies. Later we will construct suitable animal models to simulate the tumor microenvironment in the lung, and further verify the conclusions of this study. In addition, A549 cells and $\mathrm{H} 2170$ cells were selected for subsequent experiments in this study, and we will next investigate them in more NSCLC cell lines. Similarly, to further demonstrate the process of exosome secretion and exosome uptake by NSCLC cells, we will consider the identification of exosomes by nanoparticle tracking analysis (NTA).

Taken together, as a target of miR-185-5p, RAB35 promotes the synthesis and secretion of exosomes to
A

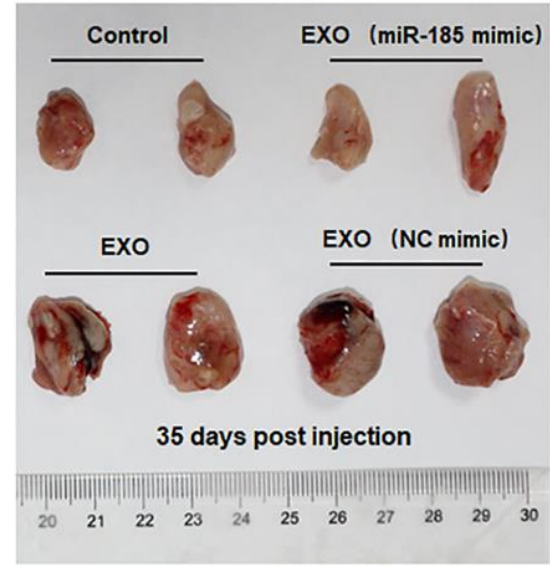

B

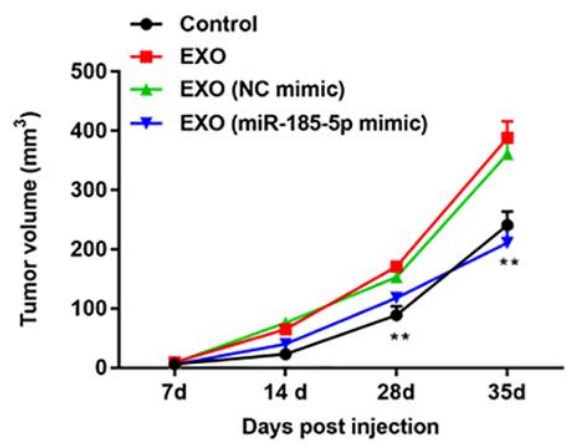

C

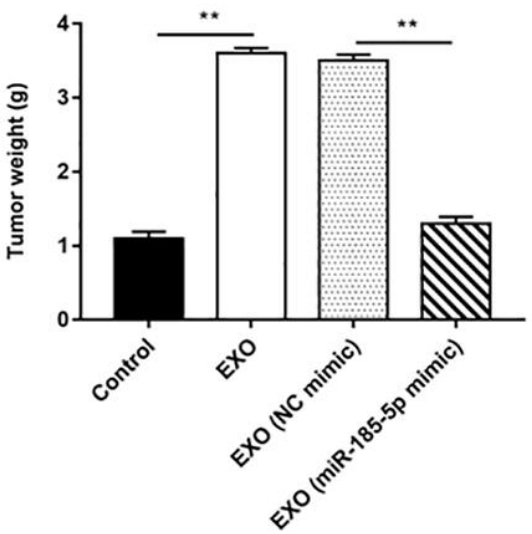

Figure 10. Exosomes from A549 cells overexpressing miR-185-5p inhibit NSCLC progression in vivo. Sixty-four nude mice were intraperitoneally injected with A549 cells, and then randomly divided into control group (normal saline), EXO group (A549 cell-derived exosomes), NC mimic group (exosomes derived from A549 cells transfected with NC mimic) and miR-185-5p mimic group (exosomes derived from A549 cells transfected with miR-185-5p mimic), with 4 nude mice in each group by intraperitoneal injection. On the days 7, 14, 28 and 35 after injection, three mice were sacrificed in each group, and tumor tissues were taken to determine the tumor volume and weight. (A) Representative tumor images at day 35 post injection. (B) Tumor volume. (C) Tumor weight. We found that injection of exosomes derived from A549 cells transfected with miR-185-5p mimic reduced tumor weight and volume in nude mice. $\mathrm{N}=4$ for each group. ${ }^{* *} p<0.01$. 
mediate NSCLC cell growth in vitro and metastasis in vivo, and our findings may become a potential idea for the treatment of NSCLC.

\section{MATERIALS AND METHODS}

\section{Animals}

Adult nude mice (20-25 g) were obtained from Henan Experimental Animal Center (Henan, China). All mice were adaptively housed for one week with free access to food and water. Sixty-four nude mice were intraperitoneally injected with A549 cells, and then divided into three groups: control group (normal saline), EXO group (A549 cell-derived exosomes), NC mimic group (exosomes derived from A549 cells transfected with NC mimic) and miR-185-5p mimic group (exosomes derived from A549 cells transfected with miR-185-5p mimic), with 4 nude mice in each group by intraperitoneal injection. On the days 7, 14, 28 and 35 after injection, three mice randomly selected in each of the four groups were euthanized, and tumor tissues were collected for subsequent studies. All animal experimental procedures were approved by the ethics committee of Xi'an No. 3 Hospital, the Affiliated Hospital of Northwest University (Xi'an, China).

\section{Clinical specimens}

Tumor tissues and adjacent tissues from 35 NSCLC patients were collected with informed consent from each subject. The age distribution of the patients was $(46.2 \pm 8.1)$ years. This study was approved by the ethics committee of Xi'an No. 3 Hospital, the Affiliated Hospital of Northwest University (Xi'an, China).

\section{Cell transfection}

The human NSCLC cell lines were obtained from ATCC (Manassas, VA, USA). The cells were cultured in RPMI 1640 medium (Gibco, Rockville, MD, USA) containing $10 \%$ FBS and $100 \mathrm{U} / \mathrm{ml}$ penicillin and 100 $\mu \mathrm{g} / \mathrm{mL}$ streptomycin (Sigma, St. Louis, MO, USA) with $5 \% \mathrm{CO}_{2}$ at $37^{\circ} \mathrm{C}$. MiR-185-5p mimic, and pcDNA$\mathrm{RAB} 35$ and their negative control were performed from RiboBio Co., Ltd (Guangzhou, China) and transfected by using RiboBio Transfection Kit (RiboBio Co., Ltd). RAB35 siRNA and Scramble were performed from Santa Cruz Biotechnology (Santa Cruz, CA, USA) and using Lipofectamine 3000 according to the manufacturer's instructions.

\section{RT-qPCR}

According to the instructions of Trizol RNA extraction kit (Invitrogen, USA), the transfected cells were added with Trizol reagent to extract the total RNA. The cDNA was obtained by transcribing RNA, in which the commercialized cDNA Reverse Transcription kit (Applied Biosystems, Carlsbad, CA, USA) was used. The thermocycler conditions: $95^{\circ} \mathrm{C}$ for $2 \mathrm{~min}$, and 35 cycles at $95^{\circ} \mathrm{C}$ for $20 \mathrm{~s}$, and $30 \mathrm{~s}$ at $55^{\circ} \mathrm{C}$, followed by $72^{\circ} \mathrm{C}$ for $60 \mathrm{~s}$. All primers were designed and synthesized by Sangon Biotech (Shanghai, China). GAPDH (RAB35) and U6 (miR-185-5p) were used as an endogenous control. The expression levels were normalized using the $2^{-\Delta \Delta \mathrm{Ct}}$ method.

\section{CCK-8 assay}

We used CCK-8 assay (Sigma-Aldrich, USA) to detect A549 or H2170 cell proliferation. A549 or H2170 cells were digested with trypsin and placed in 96-well plates. The $10 \mu \mathrm{L}$ of CCK-8 solution was added to each well at 24, 48 and $72 \mathrm{~h}$, and the mixture were placed in the incubated for $2 \mathrm{~h}$. A microplate reader (Molecular Devices, China) was used to measure the absorbance of each well at $450 \mathrm{~nm}$.

\section{Transwell cell migration and invasion assay}

Transwell assay was performed to measure A549 and $\mathrm{H} 2170$ cell invasion. Cells were seeded into the upper chamber of Transwell chambers $(8.0 \mu \mathrm{m}$ pore size; Millipore Corporation, Bedford, MA, USA) coated with Matrigel (BD Bioscience, Franklin Lakes, NJ, USA). The complete medium was added into the lower chamber. After incubation at $37^{\circ} \mathrm{C}$ for $48 \mathrm{~h}$, cells on the upper chamber were removed with cotton swabs, while cells on the lower champer were fixed with $70 \%$ ethanol and stained with $0.1 \%$ crystal violet. The invasive cells were counted under a light microscope (Olympus, Tokyo, Japan). The cell migration assay was the same as the invasion assay step, but there was no coated Matrigel in the upper chamber in the migration assay.

\section{Luciferase reporter gene analysis}

Potential target genes of miR-185-5p were predicted by Starbase 3.0 (http://starbase.sysu.edu.cn/), and RAB35 was screened out as the research object. The binding sites of RAB35 3'UTR were amplified and subcloned into the pmirGLO vectors (Promega, Madison, WI, USA) to construct RAB35 3'UTR wild-type reporter (RAB35-WT) and mutated-isoform (RAB35-MUT) encompassing mutated binding sites. The luciferase plasmids RAB35-WT and RAB35-MUT were cotransfected with miR-185-5p mimic into cells. Next, the Reporter Assay Kit (Thermo Fisher, USA) was used to detect the fluorescence intensity, which indicated the activities of the luciferase. 


\section{Western blotting}

The total protein of cells was obtained according to the reported method. The content of protein was tested by BCA kit (Solarbio, China). Then, all protein samples were denatured with SDS-PAGE loading buffer for $5 \mathrm{~min}$ in boiling water. Protein samples were detached on $10 \%$ SDS-PAGE and transferred to PVDF membranes (Bio-Rad, Hercules, CA, USA). The membranes were blocked using $5 \%$ skimmed milk for $3 \mathrm{~h}$ and then the primary antibodies were added to incubate with membranes at the $4^{\circ} \mathrm{C}$ overnight. The primary antibodies (Abcam) used for study were: GAPDH (1:800, EPR16769), RAB35 (1:700, ab152138), TSG101 (1:1500, ab125011), CD63 (1:1000, EPR21151), HSP70 (1:1000, EPR16892). Next, the TBST was used to wash the membranes five times, and then the HRP-conjugated goat anti-rabbit/mouse IgG (1:2000, Abcam) was added in the mixture at $25^{\circ} \mathrm{C}$ for $1 \mathrm{~h}$. Finally, the membranes were visualized with a substrate super ECL Plus solution (Pierce, Rockford, IL, USA). The image was processed with the Image $\mathrm{J}$ software (Rawak Software, Carlsbad, CA, USA).

\section{Exosome isolation and purification}

Cells $\left(2 \times 10^{6}\right)$ were seeded in Petri dishes with RPMI containing $10 \%$ FBS. $24 \mathrm{~h}$ later changed to RPMI without exosomes and with $10 \%$ FBS. Cell culture supernatants were collected, and exosomes were collected by differential centrifugation: the supernatant of cell culture was collected, and the cell components and dead cells were removed by lowspeed centrifugation (300 $\mathrm{g} \times 10 \mathrm{~min}, 2,000 \mathrm{~g} \times 10 \mathrm{~min}$ ) at $4^{\circ} \mathrm{C}$. The supernatant containing exosomes was retained and the cell debris was removed by highspeed centrifugation $(10,000 \quad \mathrm{~g} \times 70 \quad \mathrm{~min})$. The supernatant containing extracellular vesicles was retained and the exosomes were precipitated by ultracentrifugation $(100,000 \mathrm{~g} \times 70 \mathrm{~min})$. Appropriate amount of PBS was taken to resuspend the extracellular vesicle precipitation and then ultracentrifuged again $(100,000 \mathrm{~g} \times 70 \mathrm{~min})$ to eliminate contaminated proteins.

\section{Exosome enzyme treatment}

Previously collected exosomes were hydrolyzed with RNase $(2 \mu \mathrm{g} / \mathrm{mL})$ for $10 \mathrm{~min}$ at $37^{\circ} \mathrm{C}$, followed by the addition of RNase inhibitor $(10 \mathrm{U} / \mathrm{mL})$. Subsequently proteinase $\mathrm{K}$ was added for hydrolysis at $37^{\circ} \mathrm{C}$, after 60 min the temperature was adjusted to $60^{\circ} \mathrm{C}$ and incubated for $10 \mathrm{~min}$. Then at $4^{\circ} \mathrm{C} 110,000 \times \mathrm{g}$ after centrifugation for $70 \mathrm{~min}$, the supernatant was discarded and the resulting pellet was exosomes.

\section{Statistical analysis}

The results were performed as mean \pm SEM. All statistical analyses were exerted using the SPSS 22.0 software (Chicago, IL, USA). Student's t-test (comparison between the two groups) and One-way ANOVA test (comparison between multiple groups) were used assessed $P$ values. Values of $P<0.05$ were considered statistically significant.

\section{AUTHOR CONTRIBUTIONS}

Lina $\mathrm{Bu}$ : designed this study. Hongqing Wen, Zhiyan Liu: performed experiments. Jingjing Tang: collected data and analyzed the results. Hongqing: wrote this manuscript.

\section{CONFLICTS OF INTEREST}

The authors declare that they have no conflicts of interest.

\section{FUNDING}

This study was supported by the Xi'an Science and Technology Plan Project (201805093YX1SF27) and the Key R\&D Projects in Shaanxi Province (2019SF-208) in China.

\section{REFERENCES}

1. Su R, Zhang J, Liu X, Wei L. Identification of expression signatures for non-small-cell lung carcinoma subtype classification. Bioinformatics. 2020; 36:339-46. https://doi.org/10.1093/bioinformatics/btz557 PMID:31297509

2. Zhang GM, Luo L, Ding XM, Dong DH, Li B, Ma XC, Sun LJ. MicroRNA-126 inhibits tumor cell invasion and metastasis by downregulating ROCK1 in renal cell carcinoma. Mol Med Rep. 2016; 13: 5029-2036.

https://doi.org/10.3892/mmr.2016.5160 PMID:27108693

3. Pan XP, Wang HX, Tong DM, Li Y, Huang LH, Wang $C$. miRNA-370 acts as a tumor suppressor via the downregulation of PIM1 in hepatocellular carcinoma. Eur Rev Med Pharmacol Sci. 2017; 21:1254-63. PMID:28387905

4. Yang L, Li C, Liang F, Fan Y, Zhang S. MiRNA-155 promotes proliferation by targeting caudal-type homeobox 1 (CDX1) in glioma cells. Biomed Pharmacother. 2017; 95:1759-64.

https://doi.org/10.1016/i.biopha.2017.08.088

PMID:28962081 
5. Wang $D$, Zhang $S$, Zhao $M$, Chen F. LncRNA MALAT1 accelerates non-small cell lung cancer progression via regulating miR-185-5p/MDM4 axis. Cancer Med. 2020; 9:9138-49. https://doi.org/10.1002/cam4.3570 PMID:33146951

6. Takahashi T, Minami S, Tsuchiya Y, Tajima K, Sakai N, Suga K, Hisanaga SI, Ohbayashi N, Fukuda M, Kawahara H. Cytoplasmic control of Rab family small GTPases through BAG6. EMBO Rep. 2019; 20:e46794. https://doi.org/10.15252/embr.201846794 PMID:30804014

7. Jaé N, McEwan DG, Manavski Y, Boon RA, Dimmeler S. Rab7a and Rab27b control secretion of endothelial microRNA through extracellular vesicles. FEBS Lett. 2015; 589:3182-88.

https://doi.org/10.1016/j.febslet.2015.08.040 PMID:26348397

8. Koh HM, Song DH. Prognostic role of Rab27A and Rab27B expression in patients with non-small cell lung carcinoma. Thorac Cancer. 2019; 10:143-49. https://doi.org/10.1111/1759-7714.12919 PMID: $\underline{30480360}$

9. Hsu C, Morohashi $\mathrm{Y}$, Yoshimura S, Manrique-Hoyos N, Jung S, Lauterbach MA, Bakhti M, Grønborg M, Möbius W, Rhee J, Barr FA, Simons M. Regulation of exosome secretion by Rab35 and its GTPase-activating proteins TBC1D10A-C. J Cell Biol. 2010; 189:223-32. https://doi.org/10.1083/icb.200911018 PMID:20404108

10. Chen R, Xu X, Qian Z, Zhang C, Niu Y, Wang Z, Sun J, Zhang $X, Y u$ Y. The biological functions and clinical applications of exosomes in lung cancer. Cell Mol Life Sci. 2019; 76:4613-33.

https://doi.org/10.1007/s00018-019-03233-y PMID:31352532

11. Fan J, Xu G, Chang Z, Zhu L, Yao J. miR-210 transferred by lung cancer cell-derived exosomes may act as proangiogenic factor in cancer-associated fibroblasts by modulating JAK2/STAT3 pathway. Clin Sci (Lond). 2020; 134:807-25. https://doi.org/10.1042/CS20200039 PMID:32219336

12. Xu H, Jiao X, Wu Y, Li S, Cao L, Dong L. Exosomes derived from $\mathrm{PM} 2.5$-treated lung cancer cells promote the growth of lung cancer via the Wnt3a/ $\beta$-catenin pathway. Oncol Rep. 2019; 41:1180-88. https://doi.org/10.3892/or.2018.6862 PMID:30431139

13. Tang Y, Lin Y, Li C, Hu X, Liu Y, He M, Luo J, Sun G, Wang $\mathrm{T}$, Li W, Guo M. MicroRNA-720 promotes in vitro cell migration by targeting Rab35 expression in cervical cancer cells. Cell Biosci. 2015; 5:56. https://doi.org/10.1186/s13578-015-0047-5 PMID:26413265
14. Ge T, Wu HC, Zhou YY, Shen SM, Zhu LG, You GX. MiR296-3p may affect the proliferation and migration of non-small cell lung cancer cells via regulating RABL3. Eur Rev Med Pharmacol Sci. 2019; 23:5823-30. https://doi.org/10.26355/eurrev 201907 18321 PMID:31298353

15. Lei Y, Guo W, Chen B, Chen L, Gong J, Li W. Tumorreleased IncRNA H19 promotes gefitinib resistance via packaging into exosomes in non-small cell lung cancer. Oncol Rep. 2018; 40:3438-46. https://doi.org/10.3892/or.2018.6762 PMID:30542738

16. Alharbi M, Lai A, Guanzon D, Palma C, Zuñiga F, Perrin L, He Y, Hooper JD, Salomon C. Ovarian cancer-derived exosomes promote tumour metastasis in vivo: an effect modulated by the invasiveness capacity of their originating cells. Clin Sci (Lond). 2019; 133:1401-19. https://doi.org/10.1042/CS20190082 PMID:31227603

17. Tian C, Deng $Y$, Jin $Y$, Shi S, Bi H. Long non-coding RNA RNCR3 promotes prostate cancer progression through targeting miR-185-5p. Am J Transl Res. 2018; 10:1562-70.

PMID:29887969

18. Cao Y, Zhang R, Luo X, Yang Y. LncRNA PART1 promotes lung squamous cell carcinoma progression via miR185-5p/Six1 axis. Hum Exp Toxicol. 2021; 40:960-76. https://doi.org/10.1177/0960327120979032 PMID:33300377

19. Pei K, Zhu JJ, Wang CE, Xie QL, Guo JY. MicroRNA-185$5 p$ modulates chemosensitivity of human non-small cell lung cancer to cisplatin via targeting ABCC1. Eur Rev Med Pharmacol Sci. 2016; 20:4697-704. PMID:27906433

20. Zhu Y, Shen T, Liu J, Zheng J, Zhang Y, Xu R, Sun C, Du J, Chen Y, Gu L. Rab35 is required for Wnt5a/Dvl2induced Rac1 activation and cell migration in MCF-7 breast cancer cells. Cell Signal. 2013; 25:1075-85. https://doi.org/10.1016/i.cellsig.2013.01.015 PMID:23353182

21. Duan B, Cui J, Sun S, Zheng J, Zhang Y, Ye B, Chen $Y$, Deng W, Du J, Zhu Y, Chen Y, Gu L. EGF-stimulated activation of Rab35 regulates RUSC2-GIT2 complex formation to stabilize GIT2 during directional lung cancer cell migration. Cancer Lett. 2016; 379:70-83. https://doi.org/10.1016/j.canlet.2016.05.027 PMID:27238570

22. Yang L, Peng X, Li Y, Zhang X, Ma Y, Wu C, Fan Q, Wei S, $\mathrm{Li} \mathrm{H}$, Liu J. Long non-coding RNA HOTAIR promotes exosome secretion by regulating RAB35 and SNAP23 in hepatocellular carcinoma. Mol Cancer. 2019; 18:78. https://doi.org/10.1186/s12943-019-0990-6 PMID:30943982 
23. Villagomez FR, Medina-Contreras O, Cerna-Cortes JF, Patino-Lopez G. The role of the oncogenic Rab35 in cancer invasion, metastasis, and immune evasion, especially in leukemia. Small GTPases. 2020; 11:334-45. https://doi.org/10.1080/21541248.2018.1463895 PMID:29781368

24. Li I, Nabet BY. Exosomes in the tumor microenvironment as mediators of cancer therapy resistance. Mol Cancer. 2019; 18:32.

https://doi.org/10.1186/s12943-019-0975-5

PMID:30823926

25. Wolf-Dennen K, Kleinerman ES. Exosomes: Dynamic Mediators of Extracellular Communication in the Tumor Microenvironment. Adv Exp Med Biol. 2020; 1258:189-97.

https://doi.org/10.1007/978-3-030-43085-6_13

PMID:32767243

26. Lugini L, Valtieri M, Federici C, Cecchetti S, Meschini S, Condello M, Signore M, Fais S. Exosomes from human colorectal cancer induce a tumor-like behavior in colonic mesenchymal stromal cells. Oncotarget. 2016; 7:50086-98. https://doi.org/10.18632/oncotarget.10574

PMID:27418137

27. Shen Y, Xue C, Li X, Ba L, Gu J, Sun Z, Han Q, Zhao RC. Effects of Gastric Cancer Cell-Derived Exosomes on the Immune Regulation of Mesenchymal Stem Cells by the NF-kB Signaling Pathway. Stem Cells Dev. 2019; 28:464-76.

https://doi.org/10.1089/scd.2018.0125

PMID:30717632

28. Hannafon BN, Gin AL, Xu YF, Bruns M, Calloway $C L$, Ding WQ. Metastasis-associated protein 1 (MTA1) is transferred by exosomes and contributes to the regulation of hypoxia and estrogen signaling in breast cancer cells. Cell Commun Signal. 2019; 17:13. https://doi.org/10.1186/s12964-019-0325-7 PMID: $\underline{30782165}$

29. Qu Z, Wu J, Wu J, Luo D, Jiang C, Ding Y. Exosomes derived from HCC cells induce sorafenib resistance in hepatocellular carcinoma both in vivo and in vitro. J Exp Clin Cancer Res. 2016; 35:159. https://doi.org/10.1186/s13046-016-0430-z PMID:27716356 